\title{
Table of treaties
}

Agreement between the European Community and Canada on trade in wines and spirit drinks of 16 September 2003

101

Berne Convention for the Protection of Literary and Artistic Works (1886)

$$
5(2)
$$

6

$9(2)$

Canada-European Union Comprehensive Economic and Trade Agreement (2016)

European Patent Convention (1973) $52(2-c)$ $52(4)$

International Convention for the Protection of Performers, Producers of Phonograms and Broadcasting Organisations, 26 October 1961 (Rome Convention)

Paris Convention for the Protection of Industrial Property (1883)
6

100,103

Treaty on the Functioning of the

European Union (1957)

Article $101 \quad \mathbf{6 , 1 9}, \mathbf{2 5}, \mathbf{3 0}, \mathbf{3 1}, \mathbf{3 3}, \mathbf{4 5}$, $48,50,51,53$

Article $102 \quad \mathbf{6}, \mathbf{1 9}, \mathbf{2 5}, \mathbf{2 6}, \mathbf{3 0}, \mathbf{3 4}, \mathbf{3 7}$, $38,42,46,49,50$

90 TRIPS Agreement (1994) 87, 107, 130

$92 \quad 9(2) \quad 89$

$9410(2) \quad 90$

$13 \quad 94$

$14 \quad 90$

16(2) $\mathbf{1 0 3}$

$22 \quad 101$

$\begin{array}{lrr}\mathbf{8 2} & 23 & \mathbf{1 0 1} \\ \mathbf{8 0} & 27 & \mathbf{8 2 , 8 3}\end{array}$

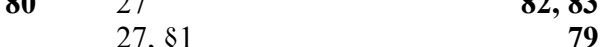

$27, \S 2 \quad 80$

$27, \S 3 \quad 80$

$31 \quad \mathbf{8 6}$

90 WIPO Copyright Treaty (1996) $\quad \mathbf{7 3 , 7 9}$

11

12
134

134 